Available online at https://www.irjst.com/

International Research Journal of Science and Technology

ISSN: $2707-3955$

DOI: https://doi.org/10.46378/irjst.2020.01012

\title{
Study of Energy States and U(5) - O(6) Transitional Symmetry of Even-Even104 - 108Cd Isotopes by Interacting Boson Model(IBM-1).
}

\section{Omar Ahmed Muaffaq}

Department of Physics, College of Science, Diyala University, Iraq

\begin{tabular}{lll} 
Paper Status & & \\
\hline Received : & Apr 2020 \\
Accepted : & May 2020 \\
Published : & Jun 2020 \\
Key Words & \\
Bosons \\
Energy Levels \\
Ibm-1 \\
Positive Parity. \\
Potential Energy Surfac, \\
Symmetry
\end{tabular}

\section{Abstract}

In this study we calculated the energy levels of low lying structure for $104-108 \mathrm{Cd}$ isotopes and the reduced transition $\mathrm{B}(\mathrm{E} 2)$ of even - even Cd nuclei for $\mathrm{A}=104,106$, 108 by using" the interaction boson model IBM-1" and compared with experimental values .The ratio $\mathrm{R}(4 / 2)$ for the energy levels for $4_{1}{ }^{+}$and $2_{1}{ }^{+}$states were also calculated for those isotopes. The $104-108 \mathrm{Cd}$ nuclei in " $\mathrm{U}(5)-\mathrm{O}(6)$ transitional symmetry" were studied .The contour plots of the potential energy surfaces (P E S) was calculate for the isotopes above .

Copyright (c) 2020: Omar Ahmed Muaffaq. This is an open access distribution, and reproduction in any medium, provided Access article distributed under the Creative Commons Attribution License the original work is properly cited License, which permits unrestricted use.

Citation: Omar Ahmed Muaffaq. "Study of Energy States and U(5) - O(6) Transitional Symmetry of Even-Even104 -108Cd Isotopes by Interacting Boson Model(IBM-1)”. International Research Journal of Science and Technology, 1 (3), 262-267, 2020.

\section{Introduction}

Digital A ((nuclear)) model was proposed by Arima and Iachello in 1974 [1]. This model was able to describe the characteristics of energy levels and nuclear structure of even - even nucleus $[1,2,3]$, with medium and heavy mass numbers by pairs of nucleons outside the closed shell that has the magical numbers $(2,8,20,28,50,82,126,184)$ where it has been treated as proton and neutron boson degrees of freedom are not distinguished. This model is called the first interactive boson model IBM-1. The order of these particles (bosons) is important for low levels of even - even nucleus, where the particles are treated as pairs of total angular momentum equal to $\mathrm{j}=0$ or $\mathrm{j}=2$ and these pairs are treated as bosons and the proton boson and neutron boson which has angular momentum $\mathrm{j}=0$ is symboled $\left(\mathrm{s}_{\pi}, \mathrm{s}_{v}\right)$ respectively $[4,5,6]$.

\footnotetext{
* Corresponding Author: Omar Ahmed Muaffaq

Department of Physics, College of Science

Diyala University, Iraq

Email: omaralqadiry@yahoo.com
}

The nutrons of $104-108 \mathrm{Cd}(\mathrm{Z}=48)$ nucleus are near to magic number $50[7,8]$. In this work, we study the transitional symmetry $\mathrm{U}(5)-\mathrm{O}(6)$ and $\mathrm{B}(\mathrm{E} 2)$ values for even - even $104-108 \mathrm{Cd}$ isotopes using IBM-1 [1] .

\section{Theory and Method of Calculation}

\subsection{Yarest -State}

The energy states are calculated using the following eq. : $\operatorname{Re}[9,10]$.

$\mathrm{H}=\sum_{\mathrm{j}=1}^{\mathrm{N}} \varepsilon \mathrm{j}+\sum_{\mathrm{i}<\mathrm{j}}^{\mathrm{N}} v \mathrm{ij}$

Whereas $\varepsilon$ is the boson energy and vij is the interaction between bosons $\mathrm{i}$ and $\mathrm{j}$. The Hamiltonian is given by [9]

$\mathrm{H}=\varepsilon n d+\mathrm{a} 0 \mathrm{pp}+\mathrm{a} 1 \mathrm{LL}+\mathrm{a} 2 \mathrm{QQ}+\mathrm{a} 3 \mathrm{~T} 3 \mathrm{~T} 3+\mathrm{a} 4 \mathrm{~T} 4 \mathrm{~T} 4$ Where a0, a1, a2, a3 and a 4 are parameters used in IBM-1 to determine the Hamiltonian function $[11,12,13]$.

nd : d-bosons operator .

$\mathrm{p}$ : operator of pairing among bosons .

$\mathrm{L}$ :Angular momentum operator. 
Q :Quadrupole operator .

T3 :Octopule oparator .

$\mathrm{T} 4$ :Hexadecapole oparator .

The Hamiltonian of the symmetry $\mathrm{U}(5) \_\mathrm{O}(6)$ is given by $[12,14]$

$\mathrm{H}=\varepsilon n d+\mathrm{a} 0 \mathrm{pp}+\mathrm{a} 1 \mathrm{LL}$

\section{2 Reduce Transition Probabilities B(E2)}

The reduced matrix elements of the E2 operator $\mathrm{T}^{\mathrm{E} 2}$ "have the form $[15,16,17]$.

$\mathrm{T}^{\mathrm{E} 2}=\alpha_{2}\left[\mathrm{~d}^{+} \mathrm{s}+\mathrm{s}^{+} \mathrm{d}\right]^{(2)}+\beta_{2}\left[\mathrm{~d}^{+} \mathrm{d}\right]^{(2)}$

Where $\left(\mathrm{s}^{+}, \mathrm{d}^{+}\right)$and $(\mathrm{s}, \mathrm{d})$ are creation and annihilation operators for $s$ and dbosons, respectively, while $\alpha 2$ and $\beta 2$ are parameters $[15,17]$

$\mathrm{B}\left(\mathrm{E} 2, \mathrm{~J}_{\mathrm{i}} \rightarrow \mathrm{J}_{\mathrm{f}}\right)=\frac{1}{2 \mathrm{~J}_{\mathrm{i}}+1}\left|\left\langle\mathrm{~J}_{\mathrm{f}}\left\|\mathrm{T}^{\mathrm{E} 2}\right\| \mathrm{J}_{\mathrm{i}}\right\rangle\right|^{2}$

\section{Results and Discussion}

\section{3 . 1 The RL/2 classification}

In order to present a comprehensive description for the application of interacting boson model IBM-1 , calculations are firstly introduced by using the IBM-1 for $104-108 \mathrm{Cd}$ isotopes that are related to dynamical symmetry $\mathrm{U}(5)-\mathrm{O}(6)$ see Table 1 . Where table 1 shows the rates of the experimental and theoretical energy "R8/2 =E( $\left.8_{1}^{+}\right) / \mathrm{E}\left(2_{1}^{+}\right), \mathrm{R} 6 / 2=\mathrm{E}\left(6_{1}^{+}\right) / \mathrm{E}\left(2_{1}^{+}\right)$ , $\mathrm{R} 4 / 2=\mathrm{E}\left(4_{1}^{+}\right) / \mathrm{E}\left(2_{1}^{+}\right)$" for even - even isotopes $(102$ $\mathrm{Cd}, 106 \mathrm{Cd}, 108 \mathrm{Cd}$ )this rates determine the symmetry for each isotopes .

The rates of the $\mathrm{E}\left(4_{1}^{+}\right) / \mathrm{E}\left(2_{1}^{+}\right), \mathrm{E}\left(6_{1}^{+}\right) / \mathrm{E}\left(2_{1}^{+}\right)$and $\left(8_{1}^{+}\right) / \mathrm{E}\left(2_{1}^{+}\right)$, values as a function of neutron numbers of $\mathrm{Cd}$ neuclei for experimental and theory values are present in figure 1 .

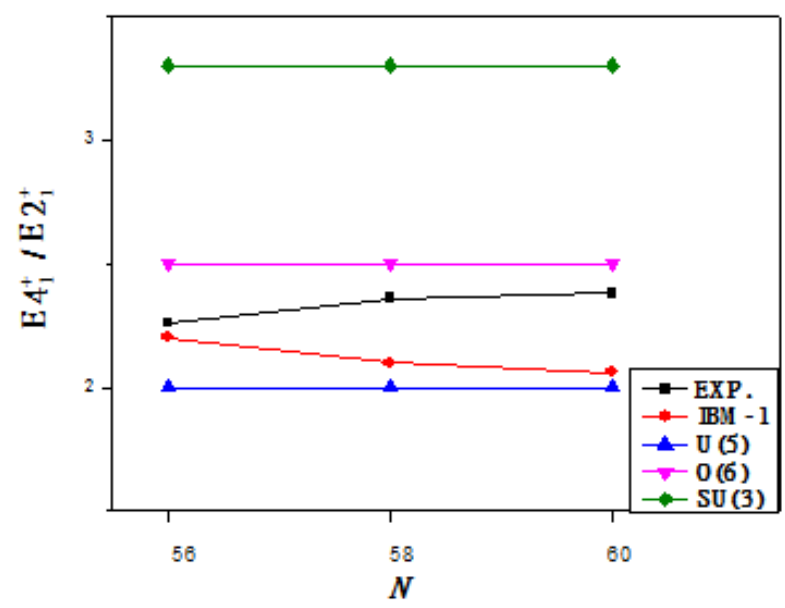

Figure 1a.

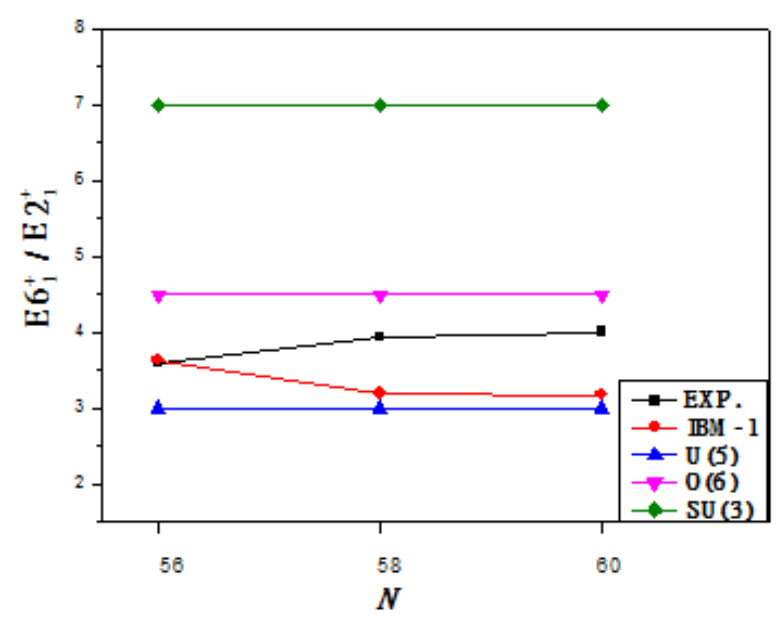

Figure 1b.

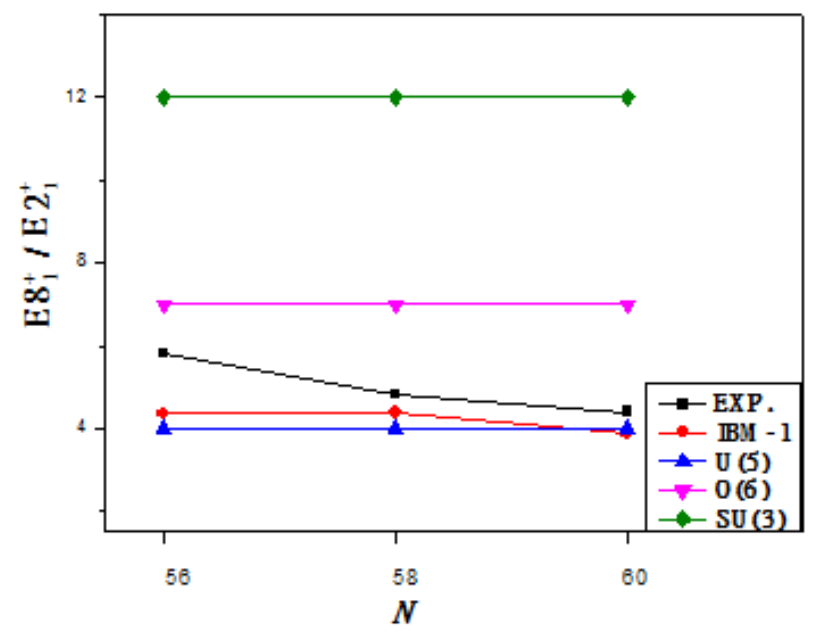

Figure 1c.

Figure 1. E $\left(\mathrm{L}_{1}^{+}\right) / \mathrm{E}\left(2_{1}^{+}\right)$values as a function of neutron numbers of $104-108 \mathrm{Cd}$ neuclei for experimental values .

From figure 1 , we can see that ${ }^{104-108} \mathrm{Cd}$ isotopes are related the $\mathrm{U}(5)-\mathrm{O}(6)$ transitional symmetry . Table 2 shows the calculated values of the Hamiltonian equation parameters using equation. It can be seen that the Hamiltonian equation operator depends on the number of BOS in this model .

Energy levels of even - even isotopes (104 Cd , 106 $\mathrm{Cd}$ and $108 \mathrm{Cd}$ ) have been classified according to the three bands ( $\mathrm{g}, \beta$ and $\gamma-$, bands) . Table 3 shows values of band's energies for each isotopes with the comparison of them with some available experimental values. It can be shown the accordance in the sequence of energy levels for each band with the ideal sequence for ground band $0^{+}, 2^{+}, 4^{+}, 6^{+}, 8^{+}$and beta - band $\mathrm{O}^{+}, 2^{+}, 4^{+}, 6^{+}, 8^{+}$and for gamma - band $2^{+}, 3^{+}, 4^{+}, 5^{+}, 6^{+}, 7^{+}, 8^{+}$. We can notice an agreement between practical and theoretical values through figures $2,3,4$. These figures show energy levels for each isotope in a way that fulfills the identical form for energy bands. 
Table 1.The rates of experimental and theoretical energy "E $\left(8_{1}^{+}\right) / \mathrm{E}\left(2_{1}^{+}\right), \mathrm{E}\left(6_{1}^{+}\right) / \mathrm{E}\left(2_{1}^{+}\right), \mathrm{E}\left(4_{1}^{+}\right) / \mathrm{E}\left(2_{1}^{+}\right)$" for even - even isotopes $(104 \mathrm{Cd}, 106 \mathrm{Cd}, 108 \mathrm{Cd})$.

\begin{tabular}{lllllll}
\hline Isotopes & EXP. & IBM-1 & EXP. & IBM-1 & EXP. & IBM-1 \\
\hline${ }^{104} \mathrm{Cd}$ & 2.26 & 2.2 & 3.6 & 3.64 & 4.4 & 3.87 \\
${ }^{106} \mathrm{Cd}$ & 2.36 & 2.1 & 3.94 & 3.2 & 4.82 & 4.38 \\
${ }^{108} \mathrm{Cd}$ & 2.38 & 2.06 & 4.01 & 3.18 & 5.82 & 4.36 \\
\hline
\end{tabular}

Table 2. The calculated values of initial parameters for Hamiltonian function operator for even - even isotopes (104 Cd , $106 \mathrm{Cd}$, $108 \mathrm{Cd}$ ) by using the program (IBM-1).

\begin{tabular}{llllllll}
\hline Isotopes & $\mathrm{N}$ & EPS & p.p & I.I & Q.Q & T3.T3 & T4.T4 \\
\hline $104 \mathrm{Cd}$ & 4 & 0.5007 & -0.0023 & 0.016 & 0.0 & 0.0 & 0.0 \\
$106 \mathrm{Cd}$ & 5 & 0.6007 & -0.0123 & 0.006 & 0.0 & 0.0 & 0.0 \\
$108 \mathrm{Cd}$ & 6 & 0.631 & -0.0123 & 0.006 & 0.0 & 0.0 & 0.0 \\
\hline
\end{tabular}

Table 3.The values of the energy bands $(\mathrm{g}, \beta, \gamma)(\mathrm{pw})$ are compared with the experimental values for the isotopes $104 \mathrm{Cd}, 106 \mathrm{Cd}$ and $108 \mathrm{Cd}$.Note : read $\mathrm{I}^{+}$for grounds $(\mathrm{g}-$ band $)$ or beta band $(\beta-$ band $)$, and read $\left(\mathrm{I}^{+}\right)$for gama bands $(\gamma-$ band $)$.

\begin{tabular}{|c|c|c|c|c|c|c|c|c|c|c|}
\hline \multirow{2}{*}{ Isotopes } & \multirow{2}{*}{$\begin{array}{l}\text { Dynamical } \\
\text { Symmetry }\end{array}$} & \multirow{2}{*}{ Band } & \multicolumn{8}{|c|}{$\mathrm{g}-$ band or $\beta$ - band $(\gamma-$ band) $(\mathrm{Mev})[18]$} \\
\hline & & & $\mathrm{O}^{+}\left(\mathrm{O}^{+}\right)$ & $2^{+}\left(2^{+}\right)$ & $4^{+}\left(3^{+}\right)$ & $6^{+}\left(4^{+}\right)$ & $8^{+}\left(5^{+}\right)$ & $\left(6^{+}\right)$ & $\left(7^{+}\right)$ & $\left(8^{+}\right)$ \\
\hline \multirow{6}{*}{$\begin{array}{l}{ }_{564}^{104} \mathrm{Cd} \\
56\end{array}$} & \multirow{6}{*}{$\mathrm{U}(5)-\mathrm{O}(6)$} & $\mathrm{g}-(\mathrm{pw})$ & 0.0 & 0.6 & 1.327 & 2.181 & 2.319 & \multirow{6}{*}{2.32} & \multirow{6}{*}{\multicolumn{2}{|c|}{$\begin{array}{l}3.16 \\
3.30 \\
\end{array}$}} \\
\hline & & g-Exp. & 0.0 & 0.658 & 1.492 & 2.370 & 2.903 & & & \\
\hline & & $\beta-(\mathrm{pw})$ & 1.001 & 1.103 & 1.829 & 2.682 & 2.682 & & & \\
\hline & & $\beta-$ Exp. & & & & 2.435 & & & & \\
\hline & & $\gamma-(\mathrm{pw})$ & 1.509 & 1.597 & 1.701 & 2.319 & 2.49 & & & \\
\hline & & $\gamma$-Exp. & & & & & & & & \\
\hline \multirow{6}{*}{$\begin{array}{l}106 \mathrm{Cd} \\
5848\end{array}$} & \multirow{6}{*}{$\mathrm{U}(5)-\mathrm{O}(6)$} & $g-(p w)$ & 0.0 & 0.662 & 1.365 & 2.111 & 2.898 & & \multirow{6}{*}{$\begin{array}{l}3.4 \\
0\end{array}$} & \\
\hline & & g-Exp. & 0.0 & 0.632 & 1.493 & 2.491 & 3.044 & & & \\
\hline & & $\beta-(\mathrm{pw})$. & 1.215 & 1.853 & 2.531 & 3.251 & 3.251 & & & \\
\hline & & $\beta$ - Exp. & 1.795 & 2.378 & 2.304 & 2.924 & & & & \\
\hline & & $\gamma-(p w)$ & 1.859 & 1.281 & 1.931 & 1.979 & 2.646 & 2.72 & & 3.50 \\
\hline & & $\gamma-\mathrm{Exp}$. & 2.144 & & & 2.104 & 2.33 & 2.50 & & 3.37 \\
\hline \multirow{6}{*}{${ }_{60}^{108} \mathrm{Cd}$} & \multirow{6}{*}{$\mathrm{U}(5)-\mathrm{O}(6)$} & $g-(p w)$ & 0.0 & 0.692 & 1.426 & 2.201 & 3.019 & & \multirow{6}{*}{$\begin{array}{l}3.5 \\
5\end{array}$} & \multirow{6}{*}{3.65} \\
\hline & & g-Exp. & 0.0 & 0.633 & 1.508 & 2.541 & & & & \\
\hline & & $\beta-(p w)$. & 1.276 & 1.943 & 2.652 & 3.403 & 3.403 & & & \\
\hline & & $\beta$ - Exp. & & 2.162 & 2.645 & & & & & \\
\hline & & $\gamma-(\mathrm{pw})$ & 1.949 & 1.342 & 2.021 & 2.069 & 2.767 & 2.84 & & \\
\hline & & $\gamma-\mathrm{Exp}$ & 1.913 & 1.601 & 2.145 & 2.239 & 2.565 & 2.81 & & \\
\hline
\end{tabular}

Table 4. The values of parameters for reduced matrix elements. $\left\langle\mathrm{I}_{\mathrm{f}}\left\|\mathrm{T}^{\mathrm{E} 2}\right\| \mathrm{I}_{\mathrm{i}}\right\rangle$ for isotopes 104Cd,106Cd and 108Cd by using ( IBST) program .

\begin{tabular}{|c|c|c|c|c|c|}
\hline Isotopes & $\mathrm{N}_{\pi}$ & $\mathrm{N}_{v}$ & $\mathrm{~N}$ & $\alpha_{2}$ & $\beta_{2}$ \\
\hline${ }^{104} \mathrm{Cd}$ & 1 & 3 & 4 & 0.18 & -0.265 \\
\hline${ }^{106} \mathrm{Cd}$ & 1 & 4 & 5 & 0.17 & -0.265 \\
\hline${ }^{108} \mathrm{Cd}$ & 1 & 5 & 6 & 0.15 & -0.265 \\
\hline
\end{tabular}

\subsection{Reduced Transition Probabilities B ( E2 )}

The calculated values of $\alpha 2$ and $\beta 2$ parameters in IBM-1 model ( Eq. 4 ) are summarized in table 4.

The experimental values of " B( E2 )" are adoped in the calculations .

Table 4 shows the relation between the parameters $\left(\alpha_{2}, \beta_{2}\right)$ and the number of bosons. It is illustrated that the values of $\alpha_{2}$ parameters decrease when the number of boson increase. The calculated values of $\mathrm{B}(\mathrm{E} 2)$ are compared with the experimental values for selected even - even isotopes. The present results are close to the experimental values. This comparison is shown in table 5. 
Table 5. The present work of B (E2) and compared with experimental values for isotopes $104 \mathrm{Cd}, 106 \mathrm{Cd}$ and 108 Cd .

\begin{tabular}{|c|c|c|}
\hline \multirow{3}{*}{$\begin{array}{l}\text { Isotopes } 104 \mathrm{Cd} \\
\mathrm{I}_{\mathrm{i}}^{+}-\mathrm{I}_{\mathrm{f}}^{+}\end{array}$} & \multicolumn{2}{|c|}{ Dynamical Symmetry "U(5) - O(6)" } \\
\hline & \multicolumn{2}{|c|}{$\mathrm{B}(\mathrm{E} 2)(\mathrm{eb})^{2}$} \\
\hline & IBM-1 (pw) & EXP.[18] \\
\hline $2_{1}^{+} \rightarrow 0_{1}^{+}$ & 0.355 & 0.300 \\
\hline $2_{2} \rightarrow 2_{1}^{+}$ & 0.572 & \\
\hline $4_{1}^{+} \rightarrow 2_{1}^{+}$ & 0.572 & 0.578 \\
\hline $6_{1}^{+} \rightarrow 4_{1}^{+}$ & 0.600 & 0.715 \\
\hline $6_{2}^{+} \rightarrow 4_{1}^{+}$ & 0.0001 & \\
\hline $2_{3}^{+} \rightarrow \mathrm{O}_{1}^{+}$ & 0.000 & \\
\hline $2_{3}^{+} \rightarrow \mathrm{O}_{2}^{+}$ & 0.306 & \\
\hline $4_{3}^{+} \rightarrow 2_{1}^{+}$ & 0.000 & \\
\hline $2_{4}^{+} \rightarrow \mathrm{O}_{1}^{+}$ & 0.000 & \\
\hline $2_{1}^{+} \rightarrow \mathrm{O}_{1}^{+}$ & 0.316 & 0.251 \\
\hline $2_{2}^{+} \rightarrow 2_{1}^{+}$ & 0.510 & 0.589 \\
\hline $4_{1}^{+} \rightarrow 2_{1}^{+}$ & 0.510 & 0.141 \\
\hline $6_{1}^{+} \rightarrow 4_{1}^{+}$ & 0.577 & \\
\hline $6_{2}^{+} \rightarrow 4_{1}^{+}$ & 0.001 & \\
\hline $2_{3}^{+} \rightarrow \mathrm{O}_{1}^{+}$ & 0.000 & \\
\hline $2_{3}^{+} \rightarrow \mathrm{O}_{2}^{+}$ & 0.273 & \\
\hline $4_{3} \rightarrow 2_{1}^{+}$ & 0.000 & \\
\hline $2_{4}^{+} \rightarrow \mathrm{O}_{1}^{+}$ & 0.000 & \\
\hline $2_{1}^{+} \rightarrow \mathrm{O}_{1}^{+}$ & 0.247 & 0.248 \\
\hline $2_{2}^{+} \rightarrow 2_{1}^{+}$ & 0.397 & 0.388 \\
\hline $4_{1}^{+} \rightarrow 2_{1}^{+}$ & 0.397 & 0.161 \\
\hline $6_{1}^{+} \rightarrow 4_{1}^{+}$ & 0.449 & \\
\hline $6_{2}^{+} \rightarrow 4_{1}^{+}$ & 0.001 & \\
\hline $2_{3}^{+} \rightarrow \mathrm{O}_{1}^{+}$ & 0.000 & \\
\hline $2_{3}^{+} \rightarrow \mathrm{O}_{2}^{+}$ & 0.212 & \\
\hline $4_{3}^{+} \rightarrow 2_{1}^{+}$ & 0.000 & \\
\hline $2_{4}^{+} \rightarrow \mathrm{O}_{1}^{+}$ & 0.000 & \\
\hline
\end{tabular}

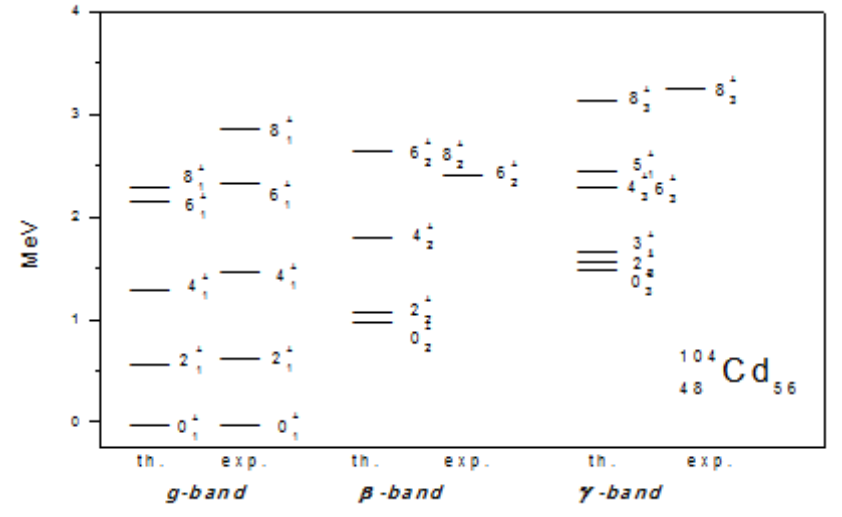

Figure 2. The energy levels for ${ }^{104} \mathrm{Cd}[18]$.

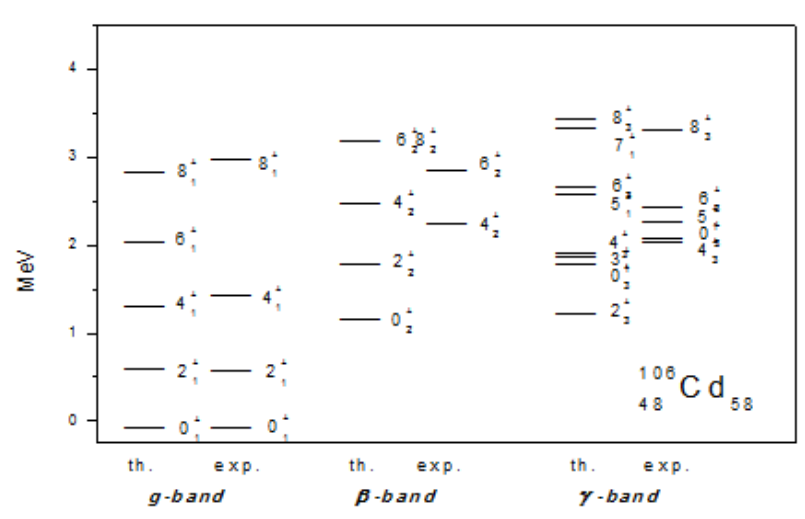

Figure 3. The energy levels for $106 \mathrm{Cd}[18$ ] . 


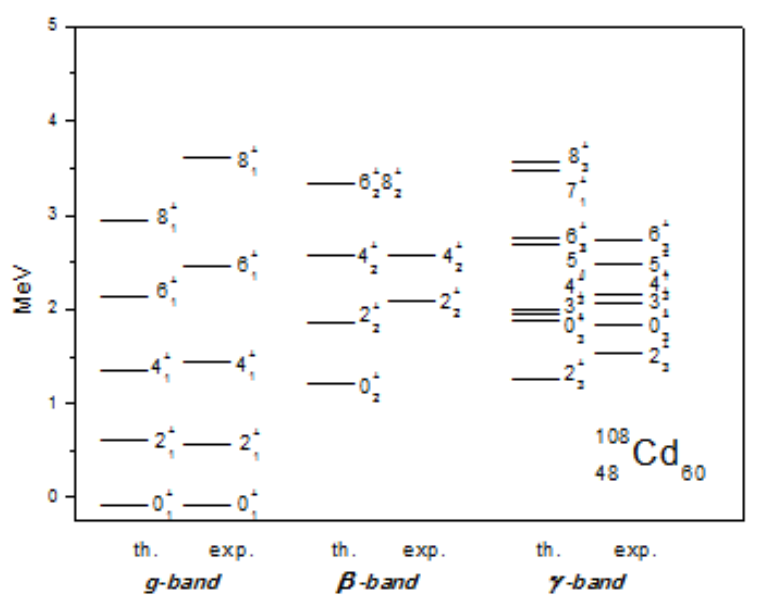

Figure 4 .The energy levels for ${ }^{108} \mathrm{Cd}[18]$.

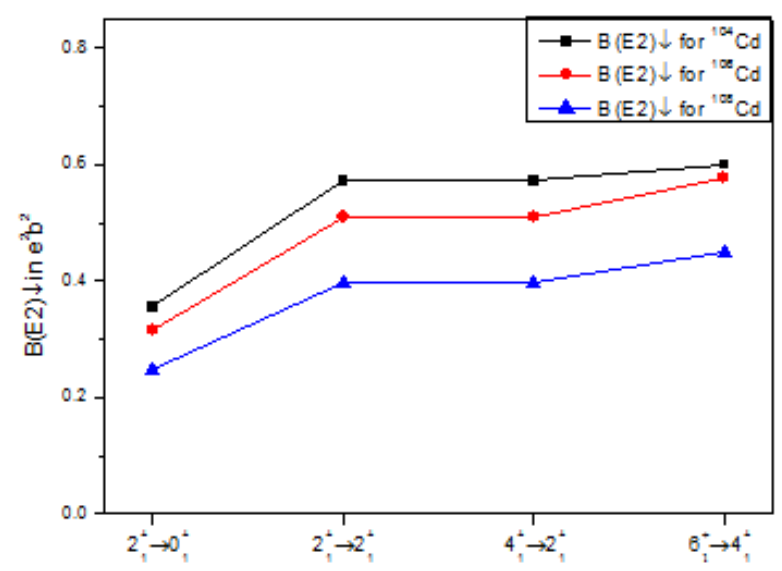

Figure 5. The electric quadrupole transitions as a function of transitions $\left(2_{1}^{+} \rightarrow \mathrm{O}_{1}^{+}\right),\left(2_{2}^{+} \rightarrow 2_{1}^{+}\right),\left(4_{1}^{+} \rightarrow 2_{1}^{+}\right)$and $\left(6_{1}^{+} \rightarrow 4_{1}^{+}\right)$for $104-108 \mathrm{Cd}$ nuclei

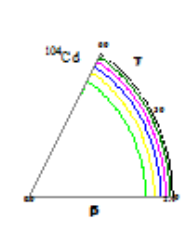

(a)
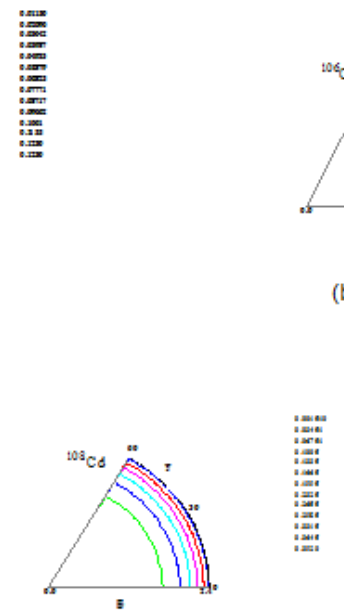

(c)

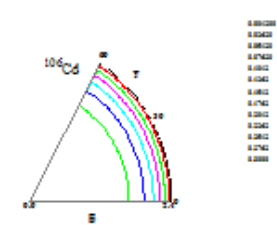

(b)
Figure (6) . potential energy surface for even $104 \mathrm{Cd} 106 \mathrm{Cd}$ and $108 \mathrm{Cd}$ isotopes .

\subsection{Potential Energy Surface ( P E S )}

By the skyrme mean field method was mapped onto the PES of the "IBM Hamiltonian" [19,20]. The expectation value of the "IBM-1 Hamiltonian" with the coherent state $\mid N, \beta, \gamma>$ is used to create the" IBM energy Surface" [ 21,22 ]. The state is a product of the boson creation operator $(v \mathrm{c}$.) with .

$$
\begin{aligned}
& |\mathrm{N}, \beta, \gamma\rangle=\frac{1}{\sqrt{\mathrm{Ni}}}\left(\mathrm{b}_{\mathrm{c}}^{+}\right)^{\mathrm{N}}|0\rangle \\
& \mathrm{b}_{\mathrm{c}}^{+}=\left(1+\beta^{2}\right)^{-1 / 2}\left\{\mathrm{~S}^{+}+\beta\left[\cos \gamma\left(\mathrm{d}_{0}^{+}\right)+\sqrt{1 / 2} \sin \gamma(\right.\right. \\
& \left.\left.\left.\mathrm{d}_{2}^{+}+\mathrm{d}_{-2}^{+}\right)\right]\right\}
\end{aligned}
$$

The energy surface as a function of $\beta$ and $\gamma$, has been given [22] .

$$
\begin{aligned}
& E(N, \beta, \alpha)= \\
& \left(1+\beta^{2}\right)+\frac{N \varepsilon d \beta^{2}}{\left(1+\beta^{2}\right)^{2}\left(\alpha_{1 \beta^{4}}+\alpha_{2 \beta^{3}} \cos 3 \gamma+\mathrm{a} 3 \beta^{2}+\alpha_{4}\right)}
\end{aligned}
$$

The calculated potential energy surface, $E(N, \beta, \gamma)$ of $104 \mathrm{Cd} 106 \mathrm{Cd}$ and $108 \mathrm{Cd}$ are shown in figure 6.

\section{Conclusion}

The" interacting boson model" was used to study the energy states of $104-108 \mathrm{Cd}$ isotopes for positive parity, the "B( E2 ) transitions " and the "potential energy surface" for the isotopes above was calculated .It is seen that the energy states and the probability $\mathrm{B}(\mathrm{E} 2)$ of those isotopes are given a good agreement with the experimental values. The even Cadmium 104 - $108 \mathrm{Cd}$ nuclei in "U(5) - O(6) symmetry" were also studied.

\section{References}

[1]. Arima, A . and Iachello, F. "Collective Nuclear States as Representations of a SU(6) Group", Phys . Rev . Lett . V. 35 , pp . 1069 1072.1975.

[2]. Islam, J . and Hossain, I . "Application of interacting boson model -1 for even $\mathrm{N}=68$ 78 for Te isotopes", ISSN 1562 - 6016 . problems of atomic Science and Technology , N5 (105) . Series : Nucleare Physics Investigations (67), pp.33 - 37.2016.

[3]. I. Hossain, I. , Hewa Abdullah, Y. and Ahmed, I . M . "Nuclear structure of ${ }^{110} \mathrm{pd}$ and ${ }^{110} \mathrm{~cd}$ Isobar by interacting boson model (IBM-1)", ISSN 1562 - 6016 . Problems of atomic science and technology, N3 (97). Series :Nuclear physics investigations (64), pp. 13 - 18. 2015.

[4]. Kumar, R ., Sharma, S . , Gupta, J . B . "Character of quasibands in ${ }^{150} \mathrm{Sm}$ using IBM”, . Arm . J . phys . 3(3) ,150 , 2010.

[5]. Cejnar, p., Jolie, J., Casten, R . F. "Quantum phase transition in the shpes of atomic nuclei", Rev . Mod . Phys . 82, 2155 [ DOI ; 10.1103 / Rev Mod Phys . 82 .2155] ,2010. 
[6]. Khudher, H. H., Hasan, A. K., Sharrad, F. I. "Calculation of energy levels , transition probiliies, and potential energy surfaces for ${ }^{120}$ - 126 Xe even - even isotopes", ISSN 2071-0186 . Ukr . J. Phys . Vol . 62, No . 2 . [DOI :10 . 15407/Ujpe 62 .02 . 0152] 2017.

[7]. Kumar, R., sharma, A. and Gupta, J. B. // Armenian J . Phys, V.3 (3) ,pp .150 . 2010.

[8]. Aphahamian, A., Brenner, D. S., Casten, R. F. and Heyda, K. // phys .lett . V . B . 140 , pp . 22.1984.

[9]. Scholten, O. et al . // Ann . phys , V . 115, pp.325. 1978.

[10]. Okhunov1, A. A., Sharrad, F. I., Anwer, A. Al-Sammarraie, Khandaker., M. U."Correspondence between phenomenological and IBM-1 models of even isotopes of $\mathrm{Yb}$ ", Chinese Physics C Vol. 39, No. 8, 084101 . 2015.

[11]. Iachello, F. "Group Theory and Nuclear spectroscopy", lecture notes in physics, Nuclear spectroscopy , Berlin , 1981.

[12]. Fadhil, I. Sharrad, Hossain, I., Ahmed, I. M., Hewa, Y., Abdullah, S., Ahmed, T., Ahmed Braz, A. S. , J . Phys . 45 , 340, 2015.

[13]. Imad, M ., Amed, Ghaith, N., Flaiyh, Hude, H., Kassim, Hewa, Y. Abdullah, Hossain, I. and Fadhil, I. Sharrad . "Microscopic description of the even - even 140-148Ba isotopes using BM, IBM and IVBM", Eur. Phys . J . plus , 132:84 DOI 10 .1140 / epjp / i $2017-11355-6.2017$.

[14]. Hossain, I., Huda, H. Kassim, Fadhil, I. Sharrad, Ahmed, A.S. "Nuclear structure of yrast bands of $180 \mathrm{Hf}, 182 \mathrm{~W}$, and $184 \mathrm{Os}$ nuclei by means of interacting boson model1", Science Asia 42 :pp.22-27. doi: 10.2306/ scienceasia 1513-1874.2016.42.022 . 2016.

[15]. Casten, R .F ., Warner, D. D., Rev . Mod . Phys . 60 ,389. 1988.

[16]. Arima, A., Iachello, F., Ann . phys .99 253. 1976.

[17]. Mushtaq, A. A 1- Jubbori, Huda, H. Kassim, Fadhil, I . sharrad, Hossin, I. "Nuclear structure of even 120-136Ba under the framework of IBM, IVBM and new method (SEF) ", Nuclear physics A 955 , pp.101-115 . 2016.

[18]. NDS ENSDF for experimental data .

[19]. Robledo, L. M., Rodriguez - Guzman, R. and Sarriguren, P., J . Phys . G : Nucl . part . phys ., $36: 115104$

DoI 10 . 1088 / 0954-3899 / 36 / 11/ 115104 . 2009.

[20]. Nomura, k. , Otsuka, T., Shimizu, N. and Guo, L. , J . Phys .Conf. Ser ., 267: 012050 .
DoI 10 . $1088 / 1742-6596 / 207 / 1 / 012050$. 2011.

[21]. Casten, R . F . and Zamfir, N .V ., phys . Rev . Lett , $87: 052503$

DoI 10 . // 03 / Phys Rev Lett . 87 . 052503. 2001.

[22]. Imam Hossain , Imad Mamdouh Ahmed, Fadhil Ismail Sharrad, Hewa yasen Abdullah, Adie Dawood Salman and Nawras Al Dahan, Chiang Mai J. Sci . 42 (4) : 996 1004

http : // epg . Science . cmu.ac. th / ejournal / contributed paper . 2015. 